\title{
Carnets
}

Revue électronique d'études françaises de l'APEF

Première Série - 2 Numéro Spécial | 2010

Littératures nationales: suite ou fin. Résistances, mutations \& lignes de fuite

\section{Cinq theses sur la litterature-monde en français: une polémique}

\section{Timo Obergöker}

\section{(2) OpenEdition}

Journals

Édition électronique

URL : http://journals.openedition.org/carnets/4955

DOI : $10.4000 /$ carnets. 4955

ISSN : 1646-7698

Éditeur

APEF

Édition imprimée

Date de publication : 1 juin 2010

Pagination : 69-85

\section{Référence électronique}

Timo Obergöker, «Cinq theses sur la litterature-monde en français: une polémique », Carnets [En ligne], Première Série - 2 Numéro Spécial | 2010, mis en ligne le 16 juin 2018, consulté le 20 avril 2019. URL http://journals.openedition.org/carnets/4955 ; DOI : 10.4000/carnets.4955

\section{(c) (i) (8)}

Carnets est mis à disposition selon les termes de la licence Creative Commons - Atribution - Pas d'utilisation commerciale 4.0 International. 


\title{
CINQ THESES SUR LA LITTERATURE-MONDE EN FRANÇAIS Une polémique
}

TIMO OBERGÖKER

Johannes Gutenberg-Universität Mainz timo_obergoeker@yahoo.fr

\begin{abstract}
Résumé
Le concept de littérature-monde n'est pas dénué de contradictions internes. Le présent article tente de s'interroger sur les fondements idéologiques de cette notion et la conjoncture internationale qui l'a fait naître. Sous formes de thèses et de manière volontairement polémique, l'article tente de montrer que la notion même est le résultat d'une littérature française dont la primauté est de plus en plus contestée. Par ailleurs, lorsque les fondateurs de ce concept déclarent la fin de la Francophonie, il est peu clair de quelle francophonie ils parlent et ils ne semblent guère familiers avec les organisations francophones. Par ailleurs, elle peut être considérée comme une adaptation fidèle des World Literatures in English de provenance anglo-saxonne sans vraiment être applicable au cas de figure francophone. Il convient également de la situer dans ce qu'on pourrait appeler, d'après Bourdieu, le "champ mondial du savoir".
\end{abstract}

\begin{abstract}
The very concept of litterrature-monde is full of contradictions. The present text presents the ideological foundations and the international conjuncture in the framework of which it arose. In form of thesis and in a polemic way, the emergence of this notion is placed into what can be called crisis of French culture which seems to go together with a crisis in Francophonie. Litterrature-monde is created on the basis of the English concept of World Literatures in English. In order to explain the success of this term, it needs to be located into what can be called with Bourdieu "the field of knowledge".
\end{abstract}

Mots-clés: Littérature-monde, Francophonie, World literatures in English, Études postcoloniales Keywords: Littérature-monde, Francophonie, World literatures in English, Postcolonial Studies 


\section{Émergence d'une notion}

Le concept de littérature-monde a bien fait verser de l'encre depuis sa première conceptualisation, et, nombreuses sont les réactions, innombrables les défenseurs et les pourfendeurs de ce concept. Le présent article cherche à y apporter un certain nombre de remarques critiques tout en tentant de le situer dans une certaine conjoncture mondiale des Lettres et des Sciences Humaines susceptibles d'élucider l'émergence de ce concept, son succès et son rayonnement international. Notre but consistera à montrer que le concept mettrait définitivement fin à la notion d'exception culturelle et ainsi sape le fondement même de ce qu'il prétend défendre: une littérature qui dise le monde, mais en français. Étant donné que ce vaste champ d'analyse est encore largement en chantier, ouvert, incertain et sujet à débats et discussions, nous préférons la forme ouverte d'un texte à thèses, désireux d'établir ainsi un plus vaste débat sur la question de la condition postcoloniale à la française. Concernant l'histoire de cette notion, il convient de remonter en 2004, année où Michel Le Bris publia un premier article dans Le Magazine littéraire. (Le Bris 2004)

Depuis sa première conceptualisation dans ce cadre, elle a connu une carrière fulgurante. Une pétition parut dans Le Monde le 16 mars 2007 et quelque temps après un volume avec les principaux signataires du manifeste. Le ton en est prophétique, le discours fortement idéologisée et exalté. En effet, en 2007 la plupart des prix littéraires furent décernés à des écrivains nés en dehors de l'Hexagone - tout comme en 1995 - d'ailleurs. Or, ce fait est considéré comme extraordinaire:

Révolution copernicienne. Copernicienne parce qu'elle révèle ce que le milieu littéraire savait déjà sans l'admettre: le centre, ce point depuis lequel était supposée rayonner une littérature franco-française, n'est plus le centre. Le centre jusqu'ici, même si de moins en moins, avait eu cette capacité d'absorption qui contraignait les auteurs venus d'ailleurs à se dépouiller de leurs bagages avant de se fondre dans le creuset de la langue et de son histoire nationale: le centre nous disent les prix d'automne, est désormais partout, aux quatre coins du monde. Fin de la Francophonie. Et naissance d'une "littérature-monde" en français. (Le Bris 2007)

Pour continuer sur un ton encore plus inspiré:

Soyons clairs: l'émergence d'une littérature-monde en langue française consciemment affirmée, ouverte sur le monde, transnationale, signe l'acte de décès de la Francophonie: Personne ne parle le francophone, ni n'écrit en francophone. La francophonie est de la lumière d'étoile morte. (Le Bris 2007) 
C'est la contribution de Jean Rouaud, qui a paru dans le livre en question, qui met l'accent sur le lien entre la langue et la nation qui s'est dissout à l'issue de la Deuxième Guerre Mondiale:

Abusés par cette vision ethnocentriste, penchés comme des rétameurs sur la phrase, résignés à cette fin prochaine, nous avions peu à peu oublié que la langue avait fait souche sur les cinq continents, qu'elle s'était développée loin des affres du vieux pays. Et que désormais déliée de son pacte avec la nation, libérée de l'étreinte de la source-mère, devenue autonome, choisie, retournée à son chant original, nourrie par d'autres aventures, n'ayant plus de compte à régler avec la langue des anciens maîtres, elle avait de nouveau à proposer [...] (Le Bris/Rouaud 2008: 21)

Cependant une réserve s'impose, s'il est une langue au monde qui a voyagé dans le monde, c'est bien le français qui a, à travers les siècles, su s'assurer de l'adhésion des gens tous azimuts à travers les continents. II est un argument quelque peu stérile (et nombriliste) de lier le rayonnement du français uniquement à l'époque coloniale et de totalement occulter qu'il persiste un attachement tout particulier à la langue française - qui d'ailleurs perdure. ${ }^{1}$ De ce fait, déjà au XVIIle siècle, loin de la mère patrie, se sont développés des textes en langue française sans qu'il y eût des rapports dominants-dominés. Pour beaucoup, sur tous les continents, l'adhésion à la langue française relève d'un choix et n'est absolument pas imputable à une quelconque situation postcoloniale. II reste, bien évidemment, le cas de figure postcolonial auquel s'ajoute toute une série d'autres constellations tout aussi complexes.

Revenons-en aux événements du mois de mars 2007. Pour prendre la mesure du tollé provoqué par ce manifeste qui donnait naissance à un livre, il est à noter qu'Abdou Diouf, président de l'Organisation Internationale de la Francophonie, publia une réplique dans les colonnes du Monde du 20 mars. Nicolas Sarkozy, alors en pleine campagne électorale, s'exprima dans Le Figaro sur le rôle de la Francophonie. II est d'ailleurs parfaitement regrettable et assez éloquent quant à un certain nombre de dérives totalitaires du manifeste qui sont peut-être dues au passé maoïste de Le Bris qu'aucune des répliques ne soit entrée dans le volume en question. Afin de remédier cet anathème latent, soient reproduits ici des extraits d'abord de la réaction d'Abdou Diouf:

Je n'ose croire que ceux dont le métier est de penser et de créer veuillent réduire le combat de la francophonie pour le respect et la promotion de la diversité des langues

\footnotetext{
${ }^{1}$ Pour s'en convaincre, on lira avec le plus grand profit l'article 'Pourquoi ils écrivent en français' paru dans $L e$ Monde du 21 mars 2009. 'L'article se consacre à cette Francophonie non issue de l'expansion coloniale; on retiendra notamment cette phrase de la Danoise Pia Andersen: "Quand on y pense, aucun écrivain ne choisit de changer de langue pour écrire en danois. Ou en russe, ou en grec. Si j'étais la France, je m'interrogerais."
} 
et des cultures à une nouvelle guerre de Cent Ans. II ne s'agit pas de lutter pour ou contre la prééminence de telle ou telle langue. II s'agit de faire en sorte que la vie de l'homme sous l'effet d'une standardisation ne se transforme en un désert de redondances et de monotonie, ou que les identités culturelles ne deviennent "meurtrières". II s'agit de construire une communauté mondiale où la recherche de convergences, d'alliances, d'interactions entre les aires de civilisation l'emportera sur les volontés hégémoniques. Et ce dessein, les francophones le revendiquent avec fierté.

Enfin, je regrette que ces idées reçues éclaboussent de leur mépris - sans le vouloir sans doute - tous ces pays que rien ne rattache au passé colonial de la France et qui ont choisi d'adhérer à la francophonie. La langue française n'appartient pas aux seuls Français, elle appartient à toutes celles et à tous ceux qui ont choisi de l'apprendre, de l'utiliser, de la féconder aux accents de leurs cultures, de leurs imaginaires, de leurs talents. Et les francophones d'autres contrées attendent des Français qu'ils ouvrent plus largement leurs manuels scolaires, leurs collections, leurs médias au talent de ces écrivains, de ces chanteurs, de ces cinéastes, de ces artistes qui ont fait le choix de créer en français. ${ }^{2}$ (Diouf 2007)

On retiendra également le texte fabuleux de l'écrivain libanais Alexandre Naijar publié le 30 mars 2007. Étant donné le silence qui entoure cette intervention également, en voici un extrait relativement long:

Au Liban, la langue française était parlée avant le Mandat français et se porte toujours très bien, soixante ans après le départ des troupes françaises du Levant. Un Libanais, un Québécois ou un Algérien qui s'exprime en français est francophone, au même titre qu'un Français de Paris, de Bretagne ou de Marseille. Tous appartiennent à une même famille ayant une langue et des valeurs en commun. Cela ne suffit-il pas? Pourquoi faut-il, au nom d'une vision réductrice de la francophonie, remettre en question ce que Senghor et nombre de personnalités majeures de notre temps ont réussi à bâtir dans un formidable élan de solidarité? Pourquoi parler de "modèles français sclérosés" et déprécier la littérature française contemporaine, qui compte encore, Dieu merci, d'excellents romanciers, dans le seul but de mieux illustrer l'apport inespéré des écrivains venus d'ailleurs, alors qu'il aurait suffi de dire que ceux-ci peuvent apporter à la littérature française des idées, des sujets, des vocables nouveaux? Le sentiment que nous avons, nous autres, écrivains francophones vivant à l'étranger, c'est que nos collègues qui s'installent en France, dès lors qu'ils décident de s'intégrer dans la vie française, ne supportent plus qu'on ne les assimile pas aux auteurs français et revendiquent la "normalité", alors que l'enjeu n'est pas là: la francophonie est notre dénominateur commun, elle n'a rien de honteux, elle n'a pas

\footnotetext{
${ }^{2}$ Le Monde des livres, 24 mars 2007.
} 
besoin d'être intégrée, puis qu'elle intègre déjà, et que, loin de diviser, elle réunit. Que nous importe l'exemple britannique! II existe entre les pays qui ont le français en partage d'autres considérations, historiques, affectives, humaines, qui font de la francophonie un concept spécifique, inimitable, qu'il serait faux de vouloir reconsidérer par référence au modèle anglo-saxon qui complexe encore nos intellectuels et qui cherche à gommer, au nom de la mondialisation prônée par l'Amérique, la diversité culturelle et le dialogue interculturel que favorise justement la francophonie. (Naijar 2007)

A l'heure qu'il est, plusieurs colloques ont été organisés cherchant à faire le point sur cette notion actuellement en plein essor. II n'est guère étonnant d'ailleurs que ce soient essentiellement les pays nordiques et anglo-saxons, qui discutent avec le plus d'intérêt cette notion. II conviendra de revenir sur ce point d'envergure. Autant d'aspects que nous proposons de discuter dans ce qui va suivre, en espérant apporter quelques nouveaux éléments à la discussion qui semble, à l'heure qu'il est, dominée par des idéologues qui recourent à un ton des plus apodictiques. Le ton quelque peu polémique de ce texte est voulu. Tentons alors de situer le présent débat dans la conjoncture mondiale dans le domaine des Lettres et des Sciences Humaines pour déceler les grandes lignes du débat qui a fait naître la notion de littérature-monde.

\section{La littérature-monde est le reflet d'une France en désarroi}

L'émergence de la littérature-monde survient à un moment où la culture française, pendant longtemps, considérée comme la culture phare dans le monde, se trouve dans une situation de plus en plus contestée. En témoignent notamment deux livres parus ces dernières années qui, en provenance du monde anglophone s'interrogent sur le devenir de la culture française. En même temps, de nombreux auteurs français s'inquiètent également d'une perte de repères culturels qui font partie du canon occidental.C'est ainsi que la Une de l'édition européenne du Time Magazine du 2 décembre 2007, The death of French culture,,provoqua une vive discussion en France sur le rôle de sa culture et de son rayonnement à l'étranger. L'auteur de l'article, Donald Morrison, y fustigeait notamment une littérature française nombriliste et intimiste qui se tient à l'écart du quotidien des Français. II en fit un livre Que reste-t-il de la culture française? publié quelques mois après, postfacé par Antoine Compagnon sous le titre Le Souci de grandeur.

Morrison procède d'une manière analogue pour chacun de ses chapitres; après avoir présenté une période de grand rayonnement de la culture, il indique les symptômes de décrépitude et ce dans tous les domaines de la vie culturelle française. Pour ce qui est du 
déclin littéraire, il s'agit là d'un passage relativement long dont les idées centrales méritent d'être citées dans leur totalité:

La situation [de la littérature française, a commencé à se détériorer au milieu du XXe siècle avec l'apparition du Nouveau Roman dont les tenants ont choisi de saborder les conventions en vigueur, que ce soit la vraisemblance de l'intrigue, en faveur de l'ivresse de l'expérimentation en donnant des résultats parfois désorientants. [...] Après les pionniers du genre - Nathalie Sarraute, Claude Simon, Alain Robbe-Grillet et Michel Butor - peu d'écrivains d'aujourd'hui se réclament du nouveau roman, qui exerce une influence persistante quoique sous-jacente. Les romans français contemporains gardent souvent un caractère expérimental, autoréférentiel, claustrophobique, si ce n'est nombriliste. [...] A la différence des romanciers du XIXe siècle qui s'emparaient de la question sociale; des écrivains engagés ceux d'avant comme ceux d'après la Deuxième Guerre Mondiale, à la différence encore des écrivains de 1968, les écrivains français d'aujourd'hui se tiennent à l'écart du monde réel, de la politique, de la mondialisation, du terrorisme [...]. (Morrison 2007: 54)

Pareille vision de la littérature française de nos jours relève tout simplement de la caricature et il semble légitime aussi de se poser la question de savoir si la tâche de la littérature est précisément celle de se faire le reflet du monde réel. Prônant une libéralisation et une fin de l'intervention de l'État dans le domaine de la culture, Morrison cherche à mettre une fin définitive à l'exception culturelle, donc à la reconnaissance du fait que la culture n'est pas une marchandise comme les autres et que, par conséquent, elle a besoin d'être protégée. ${ }^{3}$ Au demeurant, il n'en vante pas moins la force novatrice d'un certain nombre de jeunes chanteurs français, Cali, Camille et Vincent Delerm, sans se poser la question de savoir si ce n'est pas précisément l'intervention de l'État qui a permis à ces jeunes de trouver leur public, moyennant le quota à la radio dans le cadre de la loi Toubon.

Les réactions en France frôlaient à bien des reprises l'hystérie. II eût suffi cependant de réagir en argumentant et en présentant les tares argumentatives du texte. L'argumentaire de Morrison est dangereux dans la mesure où pour lui le seul critère est le succès commercial. Sa recette magique est celle d'enlever toute spécificité nationale à la culture, de surtout épargner à un étranger les difficultés (toutes relatives) de la langue française, afin d'assurer le succès d'une culture qui n'aurait en définitive plus rien de français. ${ }^{4}$

\footnotetext{
${ }^{3}$ Concernant la notion d'exception culturelle, on consultera avec profit: Regourd 2002.

${ }^{4}$ Ainsi, l'auteur critique le nombre de films français qui sont financés par l'État, pour ensuite affirmer: "Certains d'entre eux y arrivent déjà [à se passer de subventions] Cédric Klapisch avec L'Auberge espagnole en 2003 [sic], Mathieu Kassovitz avec Les Rivières pourpres, et sa suite, la série des Taxi, exploitant la veine des films d'action de Hong Kong, ou encore le récent Astérix aux Jeux Olympiques, conçu dès le départ pour le marché international, ont eu du succès auprès du grand public". (Morrison 2008, 68.).

Tous ces films-là représentent des tristes représentants de la sauce cinématographique internationale, mauvaises copies de Hollywood.
} 
Au lieu de fustiger les failles patentes dans l'argumentation du journaliste américain, la culture politique officielle se contentait de ce qu'elle sait faire le mieux: multiplier pétitions et lettres ouvertes. Ainsi, Olivier Poivre d'Arvor, le chef de culturesfrance, organisme œuvrant pour le rayonnement de la culture française à l'étranger, a publié une Lettre à nos amis américains, dans laquelle les instances de la politique culturelle officielle tombent au regard de la suprématie anglo-saxonne dans l'éternel discours justificatif:

II est vrai que depuis quelques années, de la France, en matière de culture, faute d'en parler la langue, ce sont nos artistes silencieux qui font du bruit chez vous: le mime Marceau, les silences abyssaux du commandant Cousteau, nos chorégraphes, nos circassiens... Nous résistons avec nos moyens, notre sublime aphonie, notre gêne bégayée, au chahut, au brouhaha du monde, mais nous aimerions bien, encore un peu, modestement à la française, vous impressionner. Nous faire entendre, pousser quelques cris, une ou deux colères. L'entreprise n'est pas simple, quand, avec vos puissantes industries culturelles, vos machines planétaires à projeter les images, les sons, les logiciels, les désirs, vous êtes sinon aimés, du moins respectés dans le monde depuis cinq ou six bonnes décennies. ${ }^{5}$ (Poivre d'Arvor 2008)

II est vrai que c'est notamment la Une du Time qui a provoqué une vive discussion en France sur le rôle de sa culture. Elle tombe en effet en plein déclinisme, spécialité française depuis quelques années, espèce d'auto-flagellation nationale dont témoigne des textes innombrables portant des titres emblématiques du genre La France tombe qu'il n'est point besoin de citer ici.

Un autre texte, certes moins spectaculaire et moins médiatisé mais plus cohérent dans l'argumentation et plus idéologique est celui de Perry Anderson, La Pensée tiède. Un regard critique sur la culture française, violent réquisitoire contre l'état actuel de la culture française, bien écrit et dont l'auteur ne dissimule en rien son idéologie marxiste, laquelle est explicite dès le paratexte.

Perry Anderson situe le faîte de la culture française et de son rayonnement à l'étranger sous le règne du général de Gaulle lorsque la France manifestait une véritable envie d'indépendance nationale et le désir d'assumer son rôle dans le monde:

S'il y avait un pays, à cette époque, auquel ne s'appliquait pas la notion de déclin, c'était bien la France. Dotée d'une économie vigoureuse, d'un État exceptionnellement fort, d'une politique extérieure intrépide, elle n'avait jamais fait preuve d'autant de dynamisme depuis la Belle Époque.

\footnotetext{
${ }^{5}$ Ce n'est d'ailleurs pas en coupant les moyens à des Instituts français et en renonçant systématiquement à l'emploi du français et en France et dans des contextes internationaux que l'on remédiera à l'aphonie mentionnée dans le texte.
} 
Le rayonnement du pays était aussi culturel. La création de la Ve République coïncida avec un épanouissement d'énergies intellectuelles qui mit la France à part pendant quarante ans. Rétrospectivement, le nombre des idées qui ont connu un retentissement mondial est saisissant. (Anderson 2005, 17sq)

Or, Anderson dresse également le portrait d'une France dont le déclin culturel est inéluctable: le paysage médiatique en pleine dégringolade, une littérature qui ne fait plus rêver le monde, un cinéma qui va un peu moins mal que le reste, un monde philosophique dominé par quelques pseudo-intellectuels de seconde zone... A qui la faute? Anderson incrimine la montée de l'intelligentsia de droite, incarnée pour lui par deux historiens Pierre Nora et François Furet qui seraient implicitement chargés de mettre en œuvre la suprématie intellectuelle de la droite, d'en assurer l'hégémonie intellectuelle pour reprendre le terme de Gramsci. Et c'est avec la victoire des intellectuels non-marxistes sous Mitterrand que commence pour lui le déclin de la culture française.

II me semble plus que révélateur qu'à un moment où plus que jamais les fondements mêmes du rayonnement de la culture se trouvent remis en question émerge un questionnement sur le rôle qui revient à la littérature d'expression française avec toutes les implications que cela apporte.

\section{Les défenseurs de la littérature-monde procèdent à un certain nombre d'amalgames terminologiques}

II paraît plus qu'étonnant que, de la plus formelle des manières, les adeptes de la littérature-monde décrètent la fin de la Francophonie. De laquelle d'abord? On a coutume à présent de distinguer la francophonie avec un petit $f$ de la Francophonie avec un grand $\mathrm{F} . \mathrm{Si}$ la première renvoie au simple fait de parler français, la deuxième est d'ordre plus institutionnel dans la mesure où elle renvoie à l'adhésion à l'Organisation Internationale de la Francophonie. Quant à cette dernière, il semble qu'une mise au point s'impose. Une certaine gauche a coutume de fustiger la Francophonie comme une survivance du colonialisme, tout en oubliant un certain nombre de choses. Au lendemain de la décolonisation a surgi la question du rôle qui revient à la langue française dans les anciennes colonies et au statut du français dans un monde dominé par les Etats-Unis. En témoigne particulièrement le numéro spécial Le Français, langue vivante de la revue Esprit paru en novembre 1962. Les enjeux d'une communauté francophone y sont clairement formulés:

Nous sommes désormais interdépendants: qu'un journal de langue française cesse de paraître quelque part dans le monde et c'est une défaite pour toute la 
communauté: qu'une école française de plus naisse où que ce soit dans le monde et c'est une victoire commune. II n'est sans doute pas de civilisation qui, à travers les âges, ait manifesté au même point que la française, le sens de l'accueil et de la générosité, il n'en est pas qui ait exprimé uns sens aussi élevé de l'humanisme; il n'en est pas qui ait su se faire adopter aussi universellement et qui ait marqué les peuples les plus divers. Dès lors, en œuvrant avec ferveur, avec passion, pour défendre et pour faire rayonner toujours davantage la langue et la culture françaises, nous ne pratiquons pas un quelconque impérialisme intellectuel, mais nous contribuons à maintenir certaines de plus hautes valeurs spirituelles de l'humanité. (Léger 1962: 2)

C'est d'ailleurs en déclarant la fin de la francophonie que les auteurs bafouent celles et ceux qui, au quotidien, et dans un environnement rude œuvrent pour le rayonnement de la langue et de la culture françaises dans le monde. II est à noter également que la fondation de l'Agence de Coopération Culturelle et Technique qui précède la fondation de l'Organisation Internationale de la Francophonie s'est faite en 1969 au Niger sans la participation de la France, laquelle n'a jamais demandé la fondation d'une telle organisation et qui au départ restait assez réticente, de crainte d'une visée néocolonialiste que l'on pourrait lui reprocher. ${ }^{6}$

Force est ainsi d'admettre que le reproche d'impérialisme est à nuancer car l'initiative provenait très clairement des anciennes colonies. Par ailleurs, l'Organisation Internationale de la Francophonie est une organisation internationale à laquelle aucun pays du monde n'est obligé d'adhérer. Ce sont les pays eux-mêmes qui décident d'adhérer ou non et comme toute organisation les pays membres sont parfaitement en droit de la quitter. On pourrait à la limite reprocher à cette organisation un manque de rigueur et un certain laxisme en ce qu'elle se soucie peu finalement de l'emploi de la langue française des pays adhérents dans des contextes internationaux. Par ailleurs, la majeure partie des dirigeants de l'OIF sont, à l'instar de l'actuel président Abdou Diouf, d'origine africaine. Il paraît ainsi assez injustifié de lui reprocher une visée néocolonialiste. Les initiatives que prend l'OIF visent un assez large éventail de thèmes, trop large lui reprochent d'aucuns. Outre l'emploi de la langue française, elle œuvre pour le respect des droits de l'homme, pour la démocratie et le développement durable dans les pays du Sud. Ceux qui trouvent ces idées répréhensibles ces idées sont libres de déclarer la fin de la Francophonie.

II semble ainsi que les signataires du manifeste se font une idée assez simpliste d'une organisation assez complexe qu'ils confondent sans doute avec un certain nombre de structures postcoloniales qu'on regroupe sous le terme de Françafrique. II s'agit là d'une tendance qui reproche à la France de maintenir une certaine zone d'influence en Afrique en

\footnotetext{
${ }^{6}$ On trouve d'ailleurs des arguments judicieux dans Tréan 2006. On consultera également avec un certain profit Wolton 2006.
} 
soutenant dictateurs et autres potentats. Nous ne pouvons d'ailleurs ici entrer dans ce débat qui mériterait à lui des pages.

\section{La littérature-monde s'inscrit dans une tradition anglo-saxonne qui n'est guère applicable au cas francophone}

Si le malentendu entre le monde anglo-saxon et le monde francophone n'est point chose nouvelle, depuis un certain nombre d'années la contestation provient de l'intérieur même de l'espace littéraire francophone, au sein duquel s'élèvent des voix qui se font les apôtres d'une nouvelle notion littéraire, la dite "littérature-monde" qui vise à remplacer une Francophonie prétendument en panne. La littérature-monde est l'adaptation assez fidèle du terme des World Literatures in English, notion censée remplacer celle des Commonwealth Literatures jugée trop impérialiste. ${ }^{7}$ Cette filiation est d'ailleurs revendiquée par le Michel Le Bris, fondateur de la notion de Littérature-monde, notion qu'il dépeint comme la résultante de la rencontre avec le monde anglophone, notamment avec la revue Granta de Cambridge. première revue qui cherche à conceptualiser la dite World fiction. Le Bris de raconter cette rencontre dans les termes suivants:

La "révolution Granta" allait bouleverser le paysage littéraire anglais: ce désir de monde, ce souci, par-delà tout genre d'une littérature qui dise le monde. Autrement dit, aussi l'affirmation qu'il n'est pas de "littérature pure" qui se construirait dans la mise en parenthèses préalable du monde, autoréférentielle, pur jeu de langage, texte ne renvoyant jamais qu'à d'autres textes, bref que la littérature n'est jamais vivante que lorsqu'elle entretient avec le monde un rapport un rapport d'incandescence. "Le dehors guérit" écrivait Stevenson, en ajoutant aussitôt que "tout récit de voyage est une autobiographie réussie" [...].

Une révolution, qui allait bien au-delà du travel writing, entendu comme genre, et devait donner un élan décisif à ce que Fuentes appela plus tard la world fiction. (Le Bris 2004, 58)

\footnotetext{
${ }^{7}$ Et qui est à son tour vivement critiquée par Salman Rushdie dans les Patries imaginaires: "La définition la plus proche que je pus obtenir avait une résonance ouvertement paternaliste: il apparaît que la littérature du Commonwealth est cet ensemble d'écritures créé, je crois, en langue anglaise, par des personnes qui ne sont pas elles-mêmes des Anglais blancs, ni des Irlandais, ni des citoyens des Etats-Unis d'Amérique. [...] Maintenant la 'littérature du Commonwealth' devenait une chose très désagréable. Ce n'était pas seulement un ghetto, mais un ghetto d'exclusion. Et la création d'un tel ghetto avait pour effet le sens du terme 'littérature anglaise' - que j'ai toujours considéré comme signifiant simplement de langue anglaise - pour en faire quelque chose de ségrégationniste sur les plans topographique, nationaliste et peut être même raciste." Cité dans Moura 2007, p.8. On trouvera des éléments critiques concernant la notion de littérature-monde chez Porra, 2008, On consultera également l'excellent article de Wilfert- Portal (2008).
} 
L'avènement de la littérature-monde et les tentatives de conceptualisation qui y sont attenantes sont enchevêtrées avec la parution, depuis les années 1980, de textes critiques s'interrogeant sur la condition postcoloniale, comme The Location of Culture de Homi Bhababa, Modernity at Large d'Appadurai ou bien Can the Subaltern speak de Spivak. Les arguments de ces textes se ressemblent tous plus ou moins: étant donné que les limites entre le centre et la périphérie s'effacent, il convient de repenser les limites entre le monde anciennement colonisateur et les anciennes colonies, parce que la culture telle que nous la vivons à présent est inéluctablement le résultat de plusieurs cultures qui entrent en contact créant de la sorte un "troisième espace", sorte de culture hybride entre les deux. Cette esquisse est bien évidemment tout à fait caricaturale, mais soulève la question d'envergure en quoi ces théories sont vraiment nouvelles. La critique latino-américaine des années 1950 s'est déjà posé la question de la transculturación dans ces pays multiculturels s'il en est et posé ainsi les fondements de la critique postcoloniale. Or, la mauvaise idée qu'a eue la critique de l'Amérique du Sud était d'exprimer ses théories en espagnol, langue parlée dans le monde mais qui n'a pas la côte sur le marché international du savoir. Le fait que la majeure partie de ces études provient du monde anglophone relève d'une autre question, celle de la domination de l'Université anglophone.

\section{La littérature-monde a besoin d'être située dans la République mondiale des}

\section{Lettres et du Savoir}

Nous l'avons vu, les fondateurs du concept de littérature-monde se réclament $d u$ concept de World Literatures in English, lui non plus exempt d'ambigüités et de heurts. Qui plus est, la critique postcoloniale fut, dans sa majeure partie, développée dans les pays d'inspiration anglo-saxonne et s'appuie notamment sur les penseurs d'origine indienne qui ont fait des études dans les prestigieuses universités occidentales. II s'agit là de toute une série de textes qui viennent d'ailleurs de paraître en France, un fait qui va sans doute profondément bouleverser le paysage scientifique français.

Les départements de français du monde anglophone ont, dès le début des années 1990, fait des efforts pour appliquer ces théories, enrichies de quelques bribes sommaires de Fanon et de Foucault, au monde francophone. Ces textes sont une source inépuisable pour mettre en lumière les malentendus entre les mondes anglo-saxon - celui qui détient un pouvoir discursif sans pareille et francophone dont il peine, à mon sens, à comprendre les modes de fonctionnement. C'est ainsi que les manuels universitaires et anthologies consacrés à la question - et qui sont sans exception rédigés en langue anglaise et fustigent du même coup un certain impérialisme français - constituent des objets d'analyse fabuleux quant au regard quelque peu condescendant et parfois arrogant que jette le monde anglo- 
saxon sur la France. C'est ainsi que le projet de la Francophonie est de manière simplette assimilée au fait postcolonial, créant maints malentendus comme dans le passage suivant:

These tensions are nowhere more acute than in relation to minorities originating in excolonies who have now settled in France. French speaking to a very large extent, yet culturally distinct in other ways and still marked by exclusionary memories of the colonial period, these minorities defy the political logic of francophonie by being residents and in many cases citizens of France while appearing to many among the majority population to belong elsewhere. Cutting across the binary logic that opposes "insiders" to "outsiders", they are creating what Homi Bhabha has described as a hybrid "third space" that allows for the emergence of new cultural forms "new structures of authority, [...] and new political initiatives". (Hargreaves/ Mc Kinney 1997: 4)

Ce qui est défié par la présence de Francophones nés hors-France n'est pas la Francophonie en tant que principe, mais le principe de territorialité ainsi que la politique d'immigration de la France. Cette vision différente repose également et c'est là que le bât blesse sur une vision foncièrement différente de l'État et des valeurs républicaines. Le monde anglophone peine à appréhender un certain nombre de spécificités du modèle français d'une République envisagée avec Ernest Renan comme un plébiscite quotidien, de gens qui non seulement désirent vivre ensemble, mais encore partagent un minimum de valeurs et de règles assurant justement l'unité dans la diversité, sans toutefois ériger la diversité en valeur absolue.

On peut d'ailleurs aussi bien considérer la Francophonie comme un troisième espace à la Homi Bhabha (Bhabha) 1994) en ce qu'elle représente un espace multinational permettant l'émergence de nouvelles formes culturelles et de représentation allant au-delà d'une logique purement symbolique et rhétorique. Les malentendus et mésinterprétations de ce genre mériteraient une étude à part il faut se contenter de cet exemple précis en guise d'illustration. On pourrait ainsi, avec Bourdieu et sa théorie du champ - malgré les réticences qu'on est en droit d'exprimer à l'égard de Bourdieu, développer une anatomie du champ mondial du savoir. En effet, les chercheurs, souvent réduits à des existences précaires, tentent constamment d'augmenter leur capital symbolique en publiant des articles. De nos jours, ce sont essentiellement les critères bibliométriques qui régissent la valorisation d'un texte écrit. Écrivant ces lignes, j'augmente donc potentiellement mon capital symbolique. Publiant ce texte dans une revue en dehors des revues anglophones en dehors du Royaume-Uni et des Etats-Unis cependant cette valorisation demeure toute relative. Les capitaux à la fois réel et symbolique se trouvent concentrés dans les prestigieuses universités américaines, modèle auquel aspirent toutes les universités occidentales. Autour 
de ce système doté d'un prestige hors du commun gravitent les bonnes universités du Royaume-Uni, ensuite les autres du monde anglophone. Ce système se trouve cimenté par un palmarès des Universités mondiales qui repose essentiellement sur le nombre de publications en langue anglaise dans les revues internationales en anglais.

De la sorte, la boucle se referme, les penseurs postcoloniaux voient circuler leurs idées depuis l'univers anglo-saxon et le prestige de ces Universités assure la circulation mondiale des idées lesquelles sont avidement reprises par les pays anglo-saxons et nordiques.

\section{La littérature-monde n'entraîne guère la diversité}

Toutes ces tentatives cependant sont également de plus en plus remises en cause depuis un certain nombre d'années, dans la mesure où l'on a compris que la notion aussi de postcolonialisme s'inscrit dans un champ de force délicat qui est est lui aussi déterminé aussi par des questions de pouvoir sont malheureusement souvent occultées.. C'est l'étude The Postcolonial Exotic. Marketing the margins de Graham Huggan qui a su formuler une attitude critique vis-à-vis des Postcolonial Studies de provenance nord-américaine en les situant dans le champ culturel qui les a fait naître et qui les propage. (Huggan, 2001) Étant donnée la pertinence argumentative du texte, il mérite que l'on s'y attarde quelque peu. Huggan y soulève dans un premier temps la question de savoir ce qu'est un auteur postcolonial. En effet, pour ce qui est du cas anglophone, force est de constater que la majeure partie des auteurs postcoloniaux sont d'éminents citoyens du Royaume-Uni. Par ailleurs, Huggan inscrit la présente discussion sur le fait postcolonial dans une évolution de la société du spectacle, pour reprendre une formule de Guy Debord, et dans l'anatomie dans l'échange universel de biens symboliques. Certains chercheurs reprochent notamment aux mouvements postcoloniaux de prolonger la condition coloniale, dans la mesure où les matières premières du Sud (littéraires, musicales, culturelles dans un contexte plus large) sont en quelque sorte peaufinées dans les Universités de l'Occident pour en tirer un maximum de bénéfices au sein d'un marché mondialisé du savoir.

Indissociablement liées avec la notion de mondialisation, les études postcoloniales font leur une vision euphorique du décloisonnement de la nation, de l'ouverture sur le monde, une théorie de la mondialité (worldliness) faisant fi des limites jadis imposées par l'État-nation, Les mouvements migratoires à travers le monde et les nouvelles solidarités qui en découlent lacent un défi à une vision purement territoriale de la chose littéraire, en décloisonnant les genres et en la libérant de son assise nationale. Pour tentante que puisse paraître cette approche, elle n'en représente pas moins un pas de plus vers le consommateur universel qui consomme des produits universels et homogènes. II s'agit en 
somme de remplacer un impérialisme par un autre, le colonialisme est remplacé par un d'un marché universel de la commodité, dans lequel s'inscrivent des textes littéraires consensuels qui feignent d'effacer toute différence culturelle tout en satisfaisant les besoins d'un lectorat se situant largement en Occident. Dans une perspective marxisante, mais néanmoins pertinente, Ahmad critique l'industrie mondiale à créer des termes et des textes consensuels de la manière suivante:

Rarely in the latter half of the present century has one come across so unabashed a recommendation that the world, especially the Orient - Palestine, Algeria, India - and indeed all races, white and black should be consumed in the form of those fictions of this world which are available in the bookshops of the metropolitan countries; the condition of becoming this perfect consumer, of course, is that frees oneself from stable identities of class, nation, gender. Thus is that sovereignty comes to be invested in the reader of literature, fully in command of an imperial geography...This is the imperial geography not of the colonial period but of late capitalism; commodity acquires universality, and a universal market arises across national frontiers and local costumes, while white trade joins black trade. When cultural criticism reaches the point of convergence with the global market, one might add, it becomes indistinguishable from commodity fetishism. (Ahmad 1992: 217)

Il convient d'ailleurs de ne pas oublier que nous sommes à l'heure qu'il est en présence d'une véritable industrie du postcolonial avec un marketing d'envergure dans lequel s'inscrivent toutes sortes de produits, des CDs de musique du monde et des manuels pour les étudiants des premiers cycles universitaires,. Ainsi, l'on observe une certaine labellisation de la chose littéraire qui ferait se retourner dans sa tombe Adorno, auteur du memorable essai Kulturkritik und Gesellschaft. J'argumenterais volontiers que la notion de littérature-monde est un label qui cherche à faciliter le marketing d'une certaine littérature de langue française en provenance des pays du Sud. Or les labels francophonie ou Francophonie ne font plus guère rêver car on les attache facilement et à tort à un certain imaginaire colonial de plus en plus controversé en France. Parallèlement, et le paradoxe est là, l'initiative provient de milieux très marqués à gauche, en effet, Michel Le Bris n'a jamais escamoté son passé maoïste. Ce sont donc bien souvent les défenseurs d'une ouverture de la chose culturelle qui participent en dernière conséquence à sa dévalorisation, déjà fustigée par Finkielkraut dans La Défaite de la pensée. En voulant libérer la chose culturelle de son bagage "classique", on crée en dernière conséquence des catégories aisément exploitables par les experts du marketing dans les grandes maisons d'édition, fait qui explique également pourquoi le manifeste a paru chez Gallimard dans le sixième arrondissement parisien et non pas aux Nouvelles Éditions Africaines à Lomé. 
En effet, les études littéraires et culturelles tendent dorénavant à privilégier la périphérie, porteuse d'un supposé potentiel de résistance contre le discours dominant et défiant un centre prétendument porteur d'oppression coloniale. Et c'est là que réside le paradoxe les études postcoloniales: un Occident en mal d'aventures et en manque d'idéologie comble ce désir en cherchant des textes ailleurs. En même temps, c'est bien l'Occident qui garde la mainmise sur les textes et leur (non-) canonisation. Et, puisque les textes postcoloniaux servent en premier lieu à satisfaire un besoin éminemment occidental, la qualité proprement littéraire passe parfois à l'arrière-plan pour privilégier un exotisme tempéré et accessible au grand public. II faut en convenir: le tournant et l'ouverture vers le fait postcolonial a ouvert des portes, enrichi le canon de textes littéraires en Francophonie, et il est tout à fait heureux que de nouvelles voix fassent entendre leurs voix et nous relatent le monde de leur perspective. Le danger réside dans les étiquettes souvent trop hâtivement accolées dans un pur but de commercialisation.

\section{En guise de conclusion}

De manière condensée, la question de la littérature-monde permet d'aborder autant de phénomènes de la chose littéraire de nos jours, celle de l'ailleurs et d'un exotisme souvent facile (qui fait qu'il est extrêmement difficile d'entrer dans un parc public un soir d'été sans qu'il y ait des jeunes qui font du djembé), celle du marketing littéraire, de la domination des Etats-Unis dans le monde et de tout un "paratexte festif" qui transforme la culture un événement constant et lassant. Nous avons vu que les défenseurs de la littérature-monde partent d'un postulat problématique, à savoir un lien entre la langue et la nation qui n'a dans le cas du français jamais existé. II me semble tout aussi éloquent qu'aucun des pourfendeurs de leur concept n'ait été invité à participer au recueil. A cela s'ajoute une certaine glorification de l'ailleurs, laquelle est inspirée par le monde anglophone où cependant la notion de World Literatures est tout aussi contestée. Citons, en guise de conclusion, le professeur Lapacherie de Pau qui, dans un article consacré à la littérature-monde et au festival de littérature "Étonnants voyageurs" organisé tous les ans à Saint-Malo, résume en termes suivants et il me semble qu'on ne saurait mieux dire:

Ce festival, qui se tient à Saint-Malo, ville de corsaires qui pillaient les navires marchands ennemis pour le compte du roi de France, est, comme les milliers de festivals d'été, Avignon, la Roque d'Anthéron, la Chaise-Dieu, etc. une affaire de tourisme, de media, de caméras, d'agences photographiques, d'envoyés spéciaux, de pub, d'images. C'est le royaume d'Homo festivus, cet homme nouveau qui uniformise la planète par la fête. Or, la littérature n'est pas un trait d'union; elle sépare, elle dit 
"non", c'est un tiret de séparation. Elle ne se plie pas à l'ordre du monde, fût-il divers, multiple, pluriel; elle n'est soumise à rien, surtout pas au monde. Elle est dissensus, négation, rupture, opposition. Elle s'écarte, elle se démarque, elle s'éloigne. Elle n'est pas grégaire. Si elle unit, c'est à l'idéologie, à la propagande, à la pub, au monde uniforme, tel que les Puissants le fabriquent. A quoi bon écrire, si c'est pour répéter avec des mots français les images qui défilent en continu sur tous les écrans du monde? (Lapacherie 2007) 


\section{Bibliographie}

ANDERSON, Perry (2005). La pensée tiède. Un regard critique sur la culture française, suivi de La pensée réchauffée de Pierre Nora, Paris, Gallimard.

AHMAD, Aijaz (1992). Theory: Classes, nations, literatures, Londres, Verso, 217.

BHABHA, Homi K (1994). The Location of Culture, Londres/New York, Routledge.

DIOUF, Abdou (2007). "La Francophonie, une réalité oubliée”, Le Monde 20 mars.

HARgreaves, Alec C. / Mc KInNeY, Marc (1997), Postcolonial Cultures in France, Londres/New York, Routledge.

Huggan, Graham (2001). The Postcolonial Exotic. Marketing the margins, London/New York, Routledge.

LAPACHERIE (2007), Jean-Gérard, La littérature sans le monde, Mondesfrancophones, 23 septmbre. [consulté le 24 novembre 2009] URL: www.mondesfrancophones.com/Lapacherie]

LE BRIS, Michel (2007). "Pour une littérature-monde", Le Monde, 17 mars 2007, p.1.

LE BRIS, Michel (2004), "Pour une littérature-monde", Magazine littéraire, juin 2004, p. 54.

LE BRIS, Michel, RouAND, Jean (2008). Pour une littérature-monde en français, Paris, Gallimard.

LEGER, Jean Marc (1962), “Une responsabilité commune”, Esprit, nr. spécial Le français, langue vivante, novembre, p. 1-12.

MORRISON, Donald (2008). Que reste-t il de la culture française? suivi de Le Souci de grandeur, Paris, Denoël.

MOURA, Jean Marc (2007), Littératures francophones et théorie postcoloniale (édition augmentée), Paris, PUF.

NAIJAR, Alexandre (2007). "Expliquer l'eau par l'eau", Le Monde des livres, 30 mars.

POIVRE D'ARVOR, Olivier (2008), "Lettre à nos amis américains". [consulté le 28 novembre 2009]. URL: www.culturesfrance.com/medias/userfiles/supplement.pdf

PORRA, Véronique (2008). "Pour une littérature-monde en français. Les limites d'un discours utopique", in: Intercâmbio,13, pp. 33-54.

REgouRd, Serge (2002). L'exception culturelle, Paris, PUF (Que sais-je).

TREAN, Claire (2006), La Francophonie, Paris, Le Chevalier bleu.

WILFERT-PORTAL, Blaise (2008) "La littérature française dans la mondialisation", La vie des idées, $1^{\mathrm{er}}$ juillet [consulté le 27 novembre 2009]. URL: http://www.laviedesidees.fr/La-litterature-francaisedans-la.html

Wolton (2006), Dominique, Demain la Francophonie, Paris, Gallimard. 
